\title{
Quantitative methods and gender inequalities
}

\author{
Jacqueline Scott* \\ Department of Sociology, University of Cambridge, Cambridge, UK \\ (Received 30 April 2009; final version received 23 December 2009)
}

\begin{abstract}
This paper argues that concerns that the feminist agenda is better served by qualitative not quantitative methodology were based on a rather narrow definition of feminism and a somewhat misleading portrayal of quantitative research. Using exemplar studies undertaken as part of the ESRC Research Priority Network on Gender Inequalities in Production and Reproduction (GeNet), I show how quantitative analysis can forward our understanding of the processes that underlie gender inequalities. Quantitative approaches are essential to examine the processes of selection and exclusion that reflect and create gender inequalities as manifest in changing lives and structures. Quantitative analysis of longitudinal data is used for investigating dynamic processes and different patterns of gendered resource allocation in productive and reproductive activities; whereas in-depth qualitative analysis is used to unpick the different national policy contexts for work-family balance. This can help inform how quantitative researchers (some of whom are feminists) interpret what they count.
\end{abstract}

Keywords: GeNet; quantative methods; gender inequalities; longitudinal; statistical

\section{Introduction}

Quantitative research that uses numerical or statistical information is commonplace in virtually all branches of social science. However, the widespread use of quantitative information in areas such as gender inequalities does not of itself guarantee universal acceptance of the importance of quantitative and statistical methods in gender-related research. Within the social sciences, there has been a lively and ongoing debate about the respective strengths and weaknesses of quantitative and qualitative approaches. Some of the debate has been based on an exaggerated notion of the different epistemologies. There are very few adherents to epistemologies of objective knowledge. Quantitative researchers are not naïve positivists. They acknowledge the role of social construction in measures and are wary of quantification being seen as the equivalent of scientific reasoning. They know better than most that 'statistics can lie'.

Quantitative research like qualitative research can be well or poorly designed and implemented. In the war-of-words about research methodologies, poor research design is often confused with inherent weaknesses of the method. Good quantitative research avoids 'statisticism', that puts together some arbitrarily and haphazardly assembled collection of variables that are supposed to justify a 'causal model' or, even worse, a 'measurement model' (Duncan, 1984, p. 226). The great strength of quantitative research is that it allows the understanding of patterns. As Thomas Kuhn (1961,

*Email: j1s1004@cam.ac.uk 
p. 174) wrote 'Numbers gathered without some knowledge of the regularity to be expected almost never speak for themselves. Almost certainly, they remain just numbers'. Fortunately, there are good quantitative researchers who successfully walk the tightrope of balancing theory and data, and produce inspiring analysis that advances our social understanding.

In this paper, I illustrate the strengths of quantitative methods for furthering our understanding of gender inequalities by drawing on work that is part of the Research Priority Network on Gender Inequalities in Production and Reproduction (GeNet). I examine how different research questions point to the use of different methods and how, in seeking best methodological practice, GeNet uses a range of techniques including statistical methods, state-of-the-art longitudinal analysis, as well as qualitative interviews and comparative analysis. The fact that GeNet regards quantitative methods as essential (although not sufficient) for investigating the processes underlying gender inequalities, raises the question of why, in the early stages of second wave feminism, there was such concern about the use of quantitative methods.

\section{Feminist opposition to quantitative methods}

Ann Oakley wrote a useful review article that ponders some problems with feminism and the paradigm debate in social science (Oakley, 1998). The 'paradigm debate' refers to what Oakley regards as the false construction whereby 'quantitative' and 'qualitative' methods are regarded as being in opposition. She writes:

\footnotetext{
'when academia was first challenged by feminism in the late 1960s and early 1970s, and the biases of "masculine" knowledge and women's invisibility were revealed, the argument quickly developed that "positivist quantitative research methodology" (Mies, 1983, p. 120) cannot be used uncritically to further the political goals of academic women's studies, because the voices of women as an oppressed social group were unlikely to be heard using such an approach. Accordingly, the early feminist methodology texts all celebrated qualitative methods as best suited to the project of hearing women's accounts of their experiences (see, e.g. Bowles \& Duelli-Klein, 1983; Roberts, 1981; Stanley \& Wise, 1983)'. (Oakley, 1988, p. 708).
}

The notion of gendered ways of knowing has been particularly influential in the latter part of the twentieth century. After years of ignoring feminist work, or assuming it is only relevant to women, many social scientists, including men, are turning to feminist scholarship in order to examine the difference gender makes to what we know and how we know it (e.g. Therborn, 2004). Part of the reason for the wider relevance of feminist approaches within the social sciences was due to the shift in emphasis from women to gender (McDowell, 1992).

Once the notion of gender as an analytical category comes to the fore, then new research questions arise including the gendering of aspirations and skills, domestic power relations, couple work-strategies and the gender pay gap, and of course the redefinition of work to include unpaid care-work as well as informal labour. The very focus of GeNet on gender inequalities in production and reproduction is a result of the feminist breakdown of the false dichotomy of the public-private domains that constrained earlier social science research. The recognition of the interplay between paid work and unpaid family caring activities is crucial for understanding processes that underpin ongoing gender inequalities. 
However, the concept of gender alone is not sufficient for analysing inequalities. Starting with black women's criticisms of western feminism as white, ethnocentric and middle class in its emphasis and practice, there has been increasing recognition that there are a rather complex set of cross-cutting influences that modify experiences of gender inequalities. Progress has been somewhat uneven in attempts to take on board the notion that an adequate representation of gender inequalities must simultaneously include racial, class, ethnic and other differences. It is not always possible or appropriate to focus on complex interactions, which the concept of 'intersectionality' implies, but it is necessary to bear in mind that discrimination and inequalities will interact in certain ways that depend on the context and are specific to time and place (McCall, 2005).

The importance of intersectionality is illustrated through the GeNet project by Linda McDowell that studies the complex inequalities and construction of difference among trans-national migrants. This provides an interesting example of how gender, ethnicity and class interact in the production and use of migrant bodies in the service economy in London (McDowell, 2008). The focus is on the different types of gendersexual-racialised identity work undertaken by migrants, employers (and customers) and the interactions between them. The aim is to document how a ubiquitous hegemonic heterosexual matrix is negotiated by and coerces workers as they do gender and become gendered in the workplace. It also explores what happens when workers move between societies where this matrix can take different forms. McDowell suggests that, in order to make progress in understanding inequalities in lives and structures, then detailed case studies of this type need to be combined with quantitative analysis that are better for understanding 'inter-categorical' patterns of inequalities (McDowell, 2008).

Large-scale quantitative analysis that allows for inter-categorical analysis is somewhat rare, in part, because there is very limited data that can support statistical analysis of the multiple, intersecting and complex patterns of inequalities that cross the gender, class, age and ethnic boundaries. However, analysis of this kind, although still in its theoretical and methodological infancy, is important because it can illustrate the ways different bases of discrimination and inequality interact, depending on the context.

One of the aims of GeNet is to build up a rich and nuanced account of how gender inequalities are produced and reproduced across the life course, in different contexts and across time. This requires observing gender inequalities across different time periods and at different levels, including individual, couples, households, workplace and nation. Such an ambitious aim is best served by a range of methodological approaches, as we discuss in the next section.

\section{Research Network on Gender Inequalities in Production and Reproduction (GeNet)}

GeNet involves researchers from a variety of disciplinary backgrounds including sociology, psychology, economics, demography, geography, social policy, management and law. The main aim of the network is to analyse and explain the changing dynamics of gender inequalities in contemporary society. The focus is on inequalities in productive and reproductive activities, as played out over time and in specific contexts. This entails the examination of changing lives and structures - both how lives/structures are changing and how policy can intervene effectively to promote change towards greater equality. 
Gender inequality is a well-worked topic, but the network moves the understanding of gender inequality forward from outdated and misleading static and universal accounts, to dynamic and contextualised ones. The theories, methodologies and data for conceptualisation and analysis of processes of change over time and place are newly emerging. For example, life-course perspectives, longitudinal accounts of resources flows and constraints, contextualised understanding of gender inequalities in opportunities and constraints, are vital to the Network's objectives.

The Network is methodologically diverse. In particular, it requires new quantitative analysis of large and complex data sets, such as the National Child Development Study (NCDS), The 1970 British Cohort Study (BC70), the New Millennium Cohort Study, the British Household Panel Study, the International Social Survey Programme, and the various time budget surveys. The Network has also undertaken new qualitative studies both to examine the contexts of individual choices and changing institutional policies. By bringing together both quantitative and qualitative research the Network can better illuminate the processes of selection and exclusion that reflect and create gender inequalities as manifest in changing lives and structures.

The Network consists of nine projects that address three main themes. The first theme is concerned with analysis of individual life-course pathways through to adult attainment. The second focuses on gender, ethnic and class inequalities and the third draws out the impact and implications of different social policies. All three themes pay careful attention to how individual outcomes are influenced both by inter-linked lives and the institutional circumstances in which lives are set. Both dimensions are crucial for understanding the dynamics of gender inequalities.

The way the research questions are framed in each of the three themes, points to different methodological approaches. The projects addressing pathways to adult attainment use quantitative methods which include longitudinal analysis, both to examine aggregate societal trends and individual life-course transitions and trajectories. The projects that focus on gender, ethnic and class inequalities use a mixed methods approach (Brannen, 2005) to integrate quantitative and qualitative data that support different levels of analysis and answer different types of questions. The projects looking at the impact of social policies on gender inequalities use qualitative methods in order to examine topics such as the effectiveness of corporate governance, and the evolution of UK/EU initiatives for reconciling paid work and family care. (For more details on projects see Scott, 2004).

There is no such thing as a best method for researching gender inequalities. The appropriate method is the one that is most likely to produce credible evidence that bears directly on the questions being asked, so as to achieve the research objectives. Before the fit between research questions and appropriate methods can be assessed, it is essential to have a clear statement of the broad objectives of the research and the specific questions that the project will address (Genn, 2003). This question of fit is crucial to issues of quality. GeNet is committed to methodological excellence and it seeks to raise the standards of UK social science methodology with respect to the study of gender issues. Perhaps somewhat polemically, we argue that gender studies pose a particular challenge to the quest of raising quantitative methodological standards. In part, this is because, in the earlier phase of feminist writing, qualitative methods were often seen as preferable to quantitative approaches. It is also the case that some social scientists lack confidence in numerical skills and have a fear of statistics.

One of the best ways of motivating people to use statistical tools appropriately is to focus on interesting substantive questions that require quantitative analysis. Space 
does not permit me to discuss all the GeNet projects. Rather, I will focus on the interchanges between paid and unpaid work that are so crucial to understanding ongoing gender inequalities. The careers project and the time-use project discussed below are firmly located in the quantitative paradigm, whereas the project on policy responses to work and care in the UK/EU is qualitative. However, as I will illustrate, the different methodologies combine to provide a more nuanced understanding of inequalities in paid and unpaid work.

\section{Careers project}

The careers project is about the changing occupations of men and women. Production and reproduction are both necessary activities to sustain human society, but it is often supposed that for women, participation in advanced economies and the bearing of children are incompatible (Joshi, 2002). The increase in economic opportunities for women has been offered as an explanation of low fertility; and maternal responsibility as an explanation of women's underachievement compared to men in the sphere of paid work. A key question is how men's and women's lives intersect across generations and over time in the changing processes and outcomes associated with production and reproduction. As if the question is not complex enough, very different patterns occur by race, class and geographical regions.

The task is a daunting one, but there is much existing research on which to build. For example, previous analyses of the 1946, 1958 and 1970 sequence of British birth cohort studies show the relevant economic and demographic changes that have occurred across time, as Table 1 indicates. Between those born in 1946 and 1970 the level of educational attainment changed markedly, especially for women. Table 1 shows a rise from $11 \%$ to $32 \%$ in the proportion of women with higher educational qualifications. This includes all post-school qualifications, but considering university degrees alone, the proportion rose from $3 \%$ to $17 \%$. Thus women's educational attainment was rapidly catching up with men's (at some levels overtaking them). In the labour market, female disadvantage was also rapidly diminishing. Women in the labour force from the 1946 cohort, at age 26 in 1972, were paid on average 63\% of the hourly wage received by their male contemporaries. In 1981, when the 1958 cohort were age 23 , the wage ratio had risen to $84 \%$, and by 1996 , the women in the 1970 cohort were receiving $91 \%$ of men's wages. This increase is partly attributable to the relative rise in education and the accumulation of labour force experience, but the earlier and bigger increase also reflects the introduction of the Equal Pay Act in 1975. Meanwhile women in their 20s were experiencing an even more marked change in the proportion becoming mothers (a decline from $72 \%$ of women born in 1946, to $30 \%$ born in 1970). Entry to childbearing was and still is highly differentiated with respect to educational qualifications and at age 26 there was a gap of around 50 percentage points in the proportion of each cohort who had become mothers between those with no qualifications and those with tertiary qualifications.

The interpretation of societal trends in production and reproduction requires not only careful consideration of appropriate comparable measures, but also considerable sophistication in demographic, economic and sociological theories about how the relationship between production and reproduction might have changed. For example, looking at the hourly wage of full-time workers at age 26 taps into the known costs to women's human capital of the child-bearing years. There have been marked changes in the way production and reproduction is linked over time: fertility patterns have 
Table 1. Key indicators of economic and demographic change: evidence from the British birth cohort studies.

\begin{tabular}{lccc}
\hline & \multicolumn{3}{c}{ Survey and year of birth } \\
\cline { 2 - 4 } & NSHD & NCDS & BCS70 \\
Indicator & 1946 & 1958 & 1970 \\
\hline \% With no educational qualifications & & & \\
$\quad$ Women & 42 & 14 & 5 \\
$\quad$ Men & 43 & 12 & 7 \\
\% With tertiary qualifications & & & \\
$\quad$ Women & 11 & 25 & 32 \\
$\quad$ Men & 22 & 28 & 31 \\
Ratio of women's to men's wage at age 26 (23 for & 0.63 & 0.84 & 0.91 \\
1958 cohort) & & & \\
\% of women who were mothers by age 26 & 72 & 50 & 30 \\
$\quad$ By educational quals: & & & \\
None & 81 & 69 & 53 \\
Mid-level & 65 & 47 & 36 \\
Higher & 31 & 18 & 10 \\
\% of women employed in their early 30s & & & \\
Full-time & 25 & 37 & 51 \\
Part-time & 29 & 32 & 23 \\
Median gap in employment after first child (years) & 5.5 & 2.2 & n.a \\
Sample size at age: & 32 & 33 & 30 \\
Males & 2751 & 5583 & 5447 \\
Females & 2875 & 5786 & 5772 \\
\hline
\end{tabular}

Note: NSH: Medical Research Council National Survey of Health and Development; NCDS: National Child Development Study; BCS70: 1970 British Birth Cohort Study.

Source: Table 1 Joshi (2002).

changed, women's labour force participation has increased and there have been increasing inequalities among women in occupational careers across the life course. Sorting out why some mothers pay more penalties in terms of loss of income and occupational prestige than others is an intricate puzzle that requires both theoretical understanding and empirical refinement. It is not a matter of simply gathering numbers.

One of the most staggering changes that has occurred over the past century is the speed at which women return to participation in the labour market following the birth of their first child. There has been an overall trend of ever faster rates of mothers' return to work (see Dex, Ward, \& Joshi, 2008). For example, of mothers born in 1946, $50 \%$ of them had returned to work by the time their first child was six-years old. For mothers born in 1958, 50\% had returned by two years after the birth and, of those born in 1970, it was just one year. However, these figures vary greatly for recent cohorts depending on the level of educational qualifications the mothers held, and it is those with higher education who were born in 1958 and 1970 who have returned to work fastest (less than a year after the birth of first child); whereas those with lower levels of education or no qualifications return at a much slower rate.

The inference that gender inequalities are decreasing as a result of women's faster return to the labour market is one that needs qualification. Large-scale quantitative 
analysis allows researchers to examine how the penalties paid by women in terms of occupational prestige vary according to how long they take out of the labour force. What is clear from analysis of British Cohort Survey data is that although overall there has been a decrease in the downward mobility of women across childbirth, if women have longer breaks out of the work force or return after childbirth to a part-time job, the occupational penalties in terms of downward mobility have increased over time.

Even professional women experience increasing occupational costs for taking longer periods away from work following the birth of their first child. As Figure 1 shows a teacher born between 1922 and 1953 (data from WES - the Women and Employment Survey) had a one in five chance of moving down the occupational scale after taking one year off work; for a woman taking five years off work, this increased to just over a one in four chance. For a teacher born in 1958 (data from the NCDS National Child Development Survey), she had a one in four chance of moving down the occupational scale following a one year break, which increased to a one in three chance if the gap was five years (Dex et al., 2008).

Quantitative analysis is invaluable for examining the way production and reproduction interact in terms of women's career opportunities and how this varies across time. This matters because if we can understand what exacerbates and what reduces the occupational penalty that is incurred by those who take time out to care for their families, then we can identify where policy might best intervene to help reduce inequalities. The patterns and variability are invisible until we examine the outcomes for different groups of women, who are in different occupations and who adopt different approaches to juggling work and family responsibilities. The European PartTime Work Directive, that seeks to create parity between the employment conditions
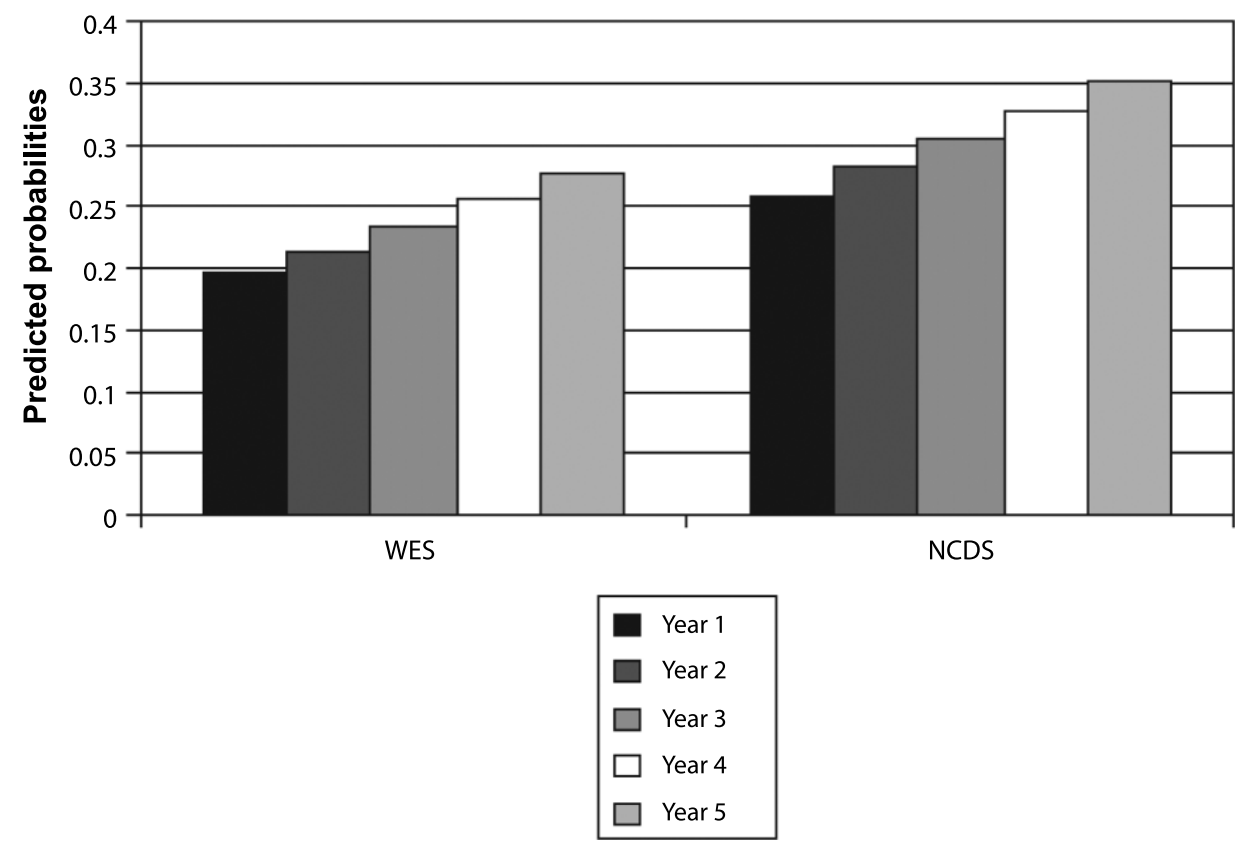

Figure 1. Predicted probabilities of downward occupational mobility after childbirth (WES and NCDS teachers by years before first return to work). Note: WES is the 1980 Women and Employment Survey and NCDS is the National Child Development Study. Source: Figure from Dex, Ward, and Joshi (2008). 
of those in part-time and full-time work, is one example of the way policy can respond to robust evidence that pinpoints the mechanisms that underpin gender inequality. The jury is still out on whether the penalty associated with the move to part-time work will lessen in the wake of the new legislation. This could enhance many women's quality of life, as part-time work can offer the employment flexibility that many carers want.

The project concerned with changing occupations and careers of men has used two unique data sources to put together this comparison of occupational change across time. The 1980 Women and Employment survey was hugely innovative for its time, because it collected full work histories from respondents and recognised the importance of understanding how family responsibilities constrained women's employment. Yet an important finding that comes from the analyses of the cohort studies is that men who take time out from employment to care for family members are prone to similar occupational penalties as women.

\section{Time-use project}

One of the advantages of quantitative research is that it is possible to derive hypotheses from existing theoretical perspectives and see how far the data support or refute these expectations. Often the empirical evidence implies the need for modification in existing theory and this in turn may lead to the generation of new hypotheses. This reciprocal back and forth between theory and empirical evidence is the way our understanding of the mechanisms that underpin gender inequalities progress. The project on gender, time allocation in paid and unpaid work, and the wage gap is an example of such hypothesis testing. The hypothesis states that a substantial part of the gender gap in wages that persists beyond the successful operation of workplace-based equal opportunities policy, is to be explained in terms of day-to-day practices of unequal division of responsibility for production and caring within households.

The hypothesis that a gendered division of domestic labour leads to a gendered wage gap is based on the assumption that women who specialise in non-waged work reduce their paid work hours, leading to a reduction in their rate of human capital formation. This is a recursive process: initial differentials in human capital and attitudes to gender roles may be the starting basis for bargaining over the distribution of paid and unpaid work roles within a heterosexual partnership. If one partner differentially specialises in unpaid work, her (rarely his) human capital declines relative to the partner who specialises more in paid-work, leading to an intensification of work-role differentiation over time.

The degree and continuity of commitment to the labour market is dependent also on public regulation. A given division of domestic labour has varying potential effects on partners' paid work participation, depending on different regime attributes. Normal weekly hours of paid work, levels and costs of childcare provisions, parental leave rights, parental leave-related employment protection, and so on, all have major consequences for participation in paid work. Regime provisions interact with the private household norms and circumstances to determine the outcome of negotiations over work-roles.

Establishing the recursive process between couples time-use allocation and changes in the 'shadow' (potential) wage of men and women requires the innovative use of longitudinal data. Gershuny (2004) has produced some interesting results looking at time-use through the life course in families. There is a statistical problem in 
focusing on family-related changes in time-use. The interesting family transitions for the purpose of studying the relationship between family conditions and individuals' time-use are relatively rare ones. Using the British Household Panel Study, which follows more than 5000 households across time, it is necessary to pool successive pairs of years to get a sample of adequate size. Even then the numbers are sufficient only to look at time-use associated with the most common transitions including acquiring a partner, the birth of a first child and grown-up children leaving home. Figure $2 \mathrm{a}$ and $2 \mathrm{~b}$ show the time-use consequences for men and women of the status transitions associated with family change, in terms of partnership and parenthood.

It can be seen that through processes of norm-driven preference and constraints, men do not change the time they devote to paid work and routine housework across the family formation sequence; whereas women reduce paid work and increase both routine housework and family care. If the partnership dissolves then he has built up his human capital while she specialises in domestic work and caring skills. As

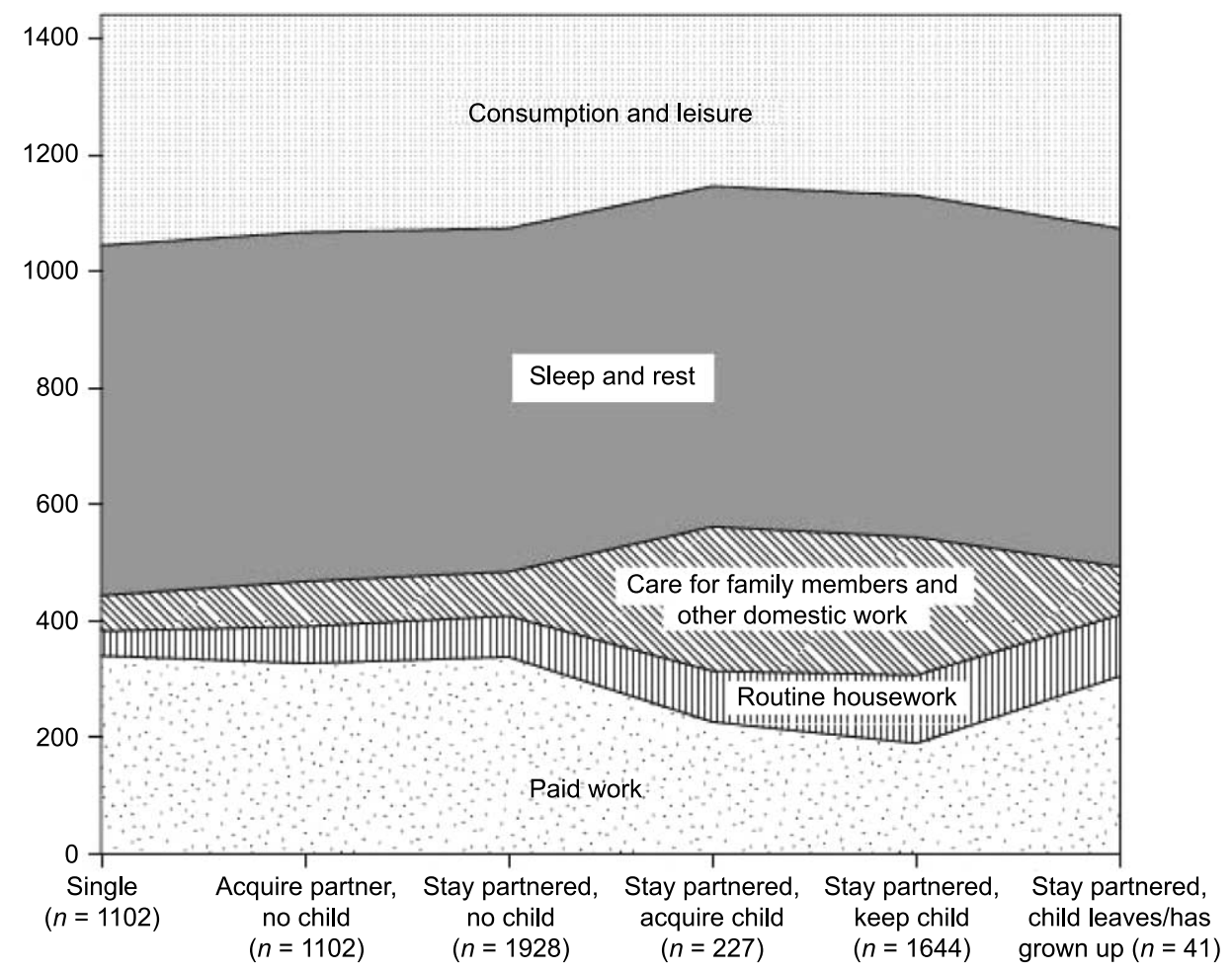

\begin{tabular}{|l|}
\hline Consumption and leisure \\
$\square$ Sleep and rest \\
$\mathbb{Q}$ Care for family members and other domestic work \\
$\square$ Routine housework \\
$\square$ Paid work \\
\hline
\end{tabular}

Figure 2a. Women's time-use (minutes per day) by family change. Source: Kan and Gershuny (2010). 

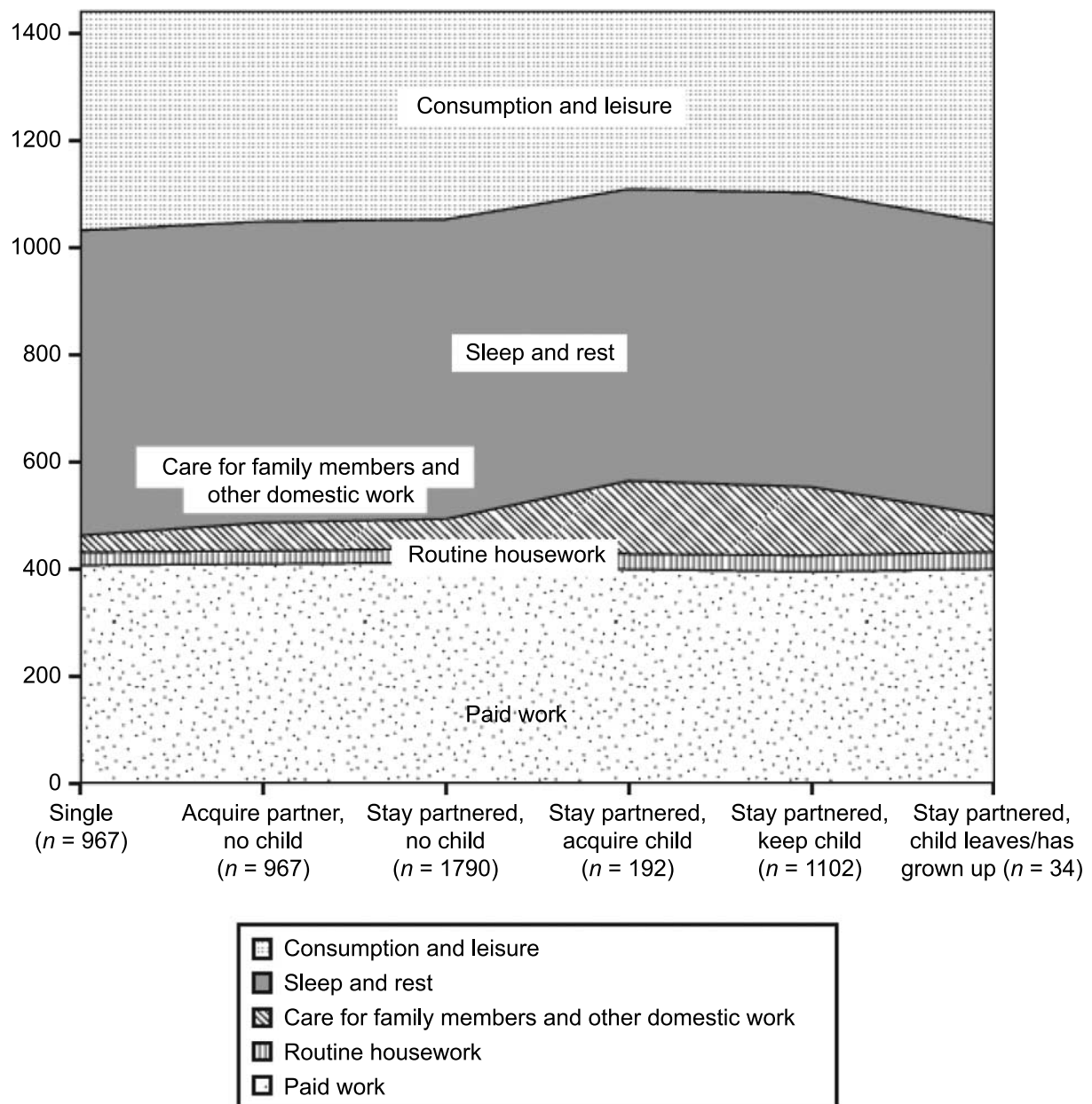

Figure 2b. Men's time-use (minutes per day) by family change. Source: Kan and Gershuny (2010).

Gershuny observes: 'he wins and she loses', in terms of marketable work skills and the associated income rewards.

\section{Policy analysis of work and care in $U K$ and $E U$}

The work and care project examines the policy discourse in comparative welfare regimes. Quantitative researchers are often dependent on such careful qualitative analysis for understanding the macro-context in which the micro-level processes are placed. As Lewis (2008) and others have pointed out, the policy regimes of many industrialised countries were designed and devised around the model of a male breadwinner family where the man worked full-time and the women cared for the family and was not expected to be employed. This male breadwinner behaviour, in its pure sense, is hardly visible in industrialised countries of the twenty-first century because of the huge increases in women's employment. 
The widespread participation of women in the labour market has gone hand in hand with concerns about declining fertility and a perceived care deficit. Thus, it is no surprise that work-family balance is high on policy agendas. Policies have grown up in different ways in different countries, and the logic underlying the policies can vary considerably from country to country, as shown in Table 2 . In principle, there are two extremes that policy regimes can adopt: they can either support adults, undifferentiated by gender, as paid workers or they can acknowledge that men and women are likely to offer different levels of contributions to the labour market. No policy regime takes the extreme adult worker position, but the USA comes pretty close to this and has only offered women rights to unpaid maternity leave since 1996. Scandinavian countries are often heralded as being more focused on providing equal opportunities to women and men, but their policies also allow women's employment contribution to be different from men's in having longer parental leave, and rights to work part-time.

Although GeNet research is focused primarily on the UK, one way of understanding what is distinctive about our own nation is to undertake cross-national analysis. In order to link specific country policies with different time-use patterns, Table 3 shows the mean time in minutes per day that men and women spend on paid and unpaid work, for the UK, the USA, Sweden, the Netherlands and West Germany. These data are taken from time diaries of a longitudinal cross-national sample (Gershuny, 2000).

Table 2. Range of models of work-family balance.

\begin{tabular}{|c|c|c|c|}
\hline Model/author & Description & Associated policies & Example countries \\
\hline $\begin{array}{l}\text { Adult worker model } \\
\text { family (Lewis, } \\
\text { 2001). Comes in } \\
\text { two forms: } \\
\text { (a) supported } \\
\text { (b) unsupported }\end{array}$ & $\begin{array}{l}\text { Men and women are } \\
\text { responsible for } \\
\text { participating in the } \\
\text { labour market. } \\
\text { Focus on getting lone } \\
\text { parents/low earners } \\
\text { into work. } \\
\text { Gender neutral, } \\
\text { equality defined as } \\
\text { sameness. }\end{array}$ & $\begin{array}{l}\text { Stimulate provision of } \\
\text { formal child-care } \\
\text { services } \\
\text { In work-benefits, tax } \\
\text { credits to low paying } \\
\text { employers. } \\
\text { Tax relief/subsidy for } \\
\text { child care if mother } \\
\text { in paid work. } \\
\text { Earned income tax } \\
\text { credits } \\
\text { No support for } \\
\text { workers, except what } \\
\text { is provided in the } \\
\text { market. } \\
\text { Little support for } \\
\text { childbearing, or } \\
\text { income replacement } \\
\text { while childbearing } \\
\text { and child-rearing }\end{array}$ & $\begin{array}{l}\text { Model encouraged in } \\
\text { EU. } \\
\text { UK since 1999, more } \\
\text { so since 2003. } \\
\text { USA }\end{array}$ \\
\hline $\begin{array}{l}\text { Gender participation } \\
\text { model, sometimes } \\
\text { called the Nordic } \\
\text { model, or 'gender- } \\
\text { differentiated } \\
\text { supported adult } \\
\text { worker model' } \\
\text { (Hobson, 2004; } \\
\text { Lewis, 2008) }\end{array}$ & $\begin{array}{l}\text { Gender equality } \\
\text { promoted, but } \\
\text { makes allowances } \\
\text { for difference. }\end{array}$ & $\begin{array}{l}\text { Generous cash support } \\
\text { for parental leave, } \\
\text { services for child } \\
\text { care and elderly } \\
\text { dependents. } \\
\text { Women to have } \\
\text { extensive periods of } \\
\text { leave and rights to } \\
\text { work part time. }\end{array}$ & $\begin{array}{l}\text { Sweden. } \\
\text { To a lesser extent } \\
\text { other Scandinavian } \\
\text { countries \& } \\
\text { Germany. }\end{array}$ \\
\hline
\end{tabular}

Source: Scott and Dex (2009). 
Table 3. Time on paid and unpaid work by men and women across nations (minutes per day).

\begin{tabular}{lcrrrr}
\hline & Netherlands & UK & USA & Sweden & West Germany \\
\hline Core domestic work & & & & & \\
$\quad$ Male & 29 & 28 & 33 & 56 & 11 \\
$\quad$ Female & 188 & 177 & 182 & 143 & 238 \\
$\begin{array}{l}\text { Other unpaid work } \\
\quad \text { Male }\end{array}$ & 84 & 83 & 97 & 117 & 84 \\
$\quad$ Female & 124 & 111 & 142 & 146 & 132 \\
Paid work & & & & & \\
$\quad$ Male & 325 & 367 & 406 & 379 & 418 \\
$\quad$ Female & 94 & 178 & 187 & 262 & 168 \\
Total work & & & & & 513 \\
$\quad$ Male & 438 & 478 & 536 & 552 & 538 \\
$\quad$ Female & 406 & 466 & 511 & 551 & \\
\hline
\end{tabular}

Source: Gershuny (2000).

Table 3 makes it clear that women in all these countries do a greater share of unpaid work than men. However, two other facts about the gender division of work are also worth noting. First adding up women's and men's paid and unpaid work leads to near equality in the amounts of total work done by men and women, or men doing slightly more total work than women (the only exception being West Germany). Such figures suggest that claims of the 'double shift' (Hochschild, 1989) may be exaggerated. Second, the average amounts of domestic work and paid work varies by country as well as by gender, with relatively high total work hours in the USA, Sweden and West Germany and lowest total work hours in the Netherlands. In Sweden, women are spending more time on core domestic work than men, despite an explicit policy commitment to gender equality. Nevertheless there is some evidence that policies supporting equality have some effect. The figures show Swedish men having the highest core domestic work contribution of these countries and Swedish women the least. However, even in Sweden, equality of unpaid domestic work seems an elusive goal.

\section{Conclusion}

There is a good news and a bad news story to be told about progress in gender equality over the past half-century. The good news is that there is a plenty of evidence to point to ways in which gender inequalities have been reduced. The bad news is that there is still a long way to go before gender equality is reached. Understanding the nuanced picture and increasing our knowledge of the mechanisms that reproduce gender inequalities in production and reproduction requires both quantitative and qualitative research. Some readers will remain unconvinced that quantitative research can help feminist inquiry. They will insist that women's experiences cannot be reduced to numbers. No serious social scientist would claim that they could be. Qualitative research is important for understanding people's experiences of discrimination in particular settings and also for probing women's own interpretations and understanding of their situations. Qualitative research is also invaluable for exploring the policy contexts that influence the opportunities and constraints that shape people's lives. 
Thus qualitative research can help inform the way that quantitative researchers (some of whom are feminists) interpret what they count.

Women's experiences also partly reflect the very different social realities that are associated with a whole range of socio-economic characteristics, including class background, education and occupational skills. One strength of quantitative research is its ability to identify the patterns and processes by which gender inequalities are passed on or modified from one generation to the next. Increasingly, such analysis takes seriously the way that gender intersects with other influences on (dis)advantage, including race and age. Quantitative research has provided a solid evidence base for the way gender inequalities have increased among women over recent decades, varying in particular by education and ethnicity.

In this paper, I have used, as an exemplar, projects that examine the relationship between paid and unpaid work. Some of the research questions posed are crucially influenced by feminist thought and agendas. A nuanced understanding of the over time changes in the way paid and unpaid work inter-relate and contribute to gender inequalities necessitates careful longitudinal and comparative analysis. The challenge of reaching greater equality in the distribution of paid and unpaid work is a feminist issue. The study of gender inequalities in production and reproduction demands the best research practice. This, in turn, requires selection of the most appropriate methodology for the research questions, and must include quantitative methods.

\section{Acknowledgements}

I gratefully acknowledge support for this research from a grant by the Economic and Social Research Council (RES-225-25-1001) which funds the ESRC Research Priority Network on Gender Inequalities in Production and Reproduction.

\section{Notes on contributor}

Jacqueline Scott is Professor in Empirical Sociology at the University of Cambridge and a Fellow of Queens' College. She directs the ESRC's Research Priority Network in Gender Inequalities in Production and Reproduction (GeNet). She has recently co-edited Women and Employment: Changing Lives and New Challenges (Edward Elgar, 2008) and Gender Inequalities in the 21st Century: New Barriers and Continuing Constraints (Edward Elgar, 2001).

\section{References}

Bowles, G., \& Duelli-Klein, R. (Eds.). (1983). Theories of women's studies. London: Routledge.

Brannen, J. (2005). Mixing methods: The entry of qualitative and quantitative approaches into the research process. International Journal of Social Research Methodology, 8(3), 173184.

Dex, S., Ward, K., \& Joshi, H. (2008). Changes in women's occupations and occupational mobility over 25 years. In J. Scott, S. Dex, \& H. Joshi (Eds.), Women and employment: Changing lives and new challenges (pp. 54-80). Cheltenham: Edward Elgar.

Duncan, O. (1984). Notes on social measurement: Historical and critical. New York: Russell Sage Foundation.

Genn, H. (2003). Assessing quality in grant applications: Reflections from the experience on the ESRC Grants Board. Paper presented for the ESRC Research Methods Programme. Retrieved April 16, 2009, from, http://www.ccsr.ac.uk/methods/projects/buxton/Genn.pdf

Gershuny, J. (2000). Changing times: Work and leisure in post industrial society. Oxford: Oxford University Press. 
Gershuny, J. (2004). Time through the life-course in the family. In J. Scott, J. Treas, \& M. Richards (Eds.), The Blackwell companion to sociology of families (pp. 158-178). Oxford: Blackwell.

Hobson, B. (2004). The Individualised worker, the gender participatory and the gender equity models in Sweden. Social Policy and Society, 3(1), 75-84.

Hochschild, A. (1989). The second shift: Working parents and the revolution at home. London: Piatkus.

Joshi, H. (2002). Production, reproduction and education: Women, children and work in a British perspective. Population and Development Review, 28(2), 445-474.

Kan, M.-Y., \& Gershuny, J. (2010). Gender segregation and bargaining in domestic labour. In J. Scott, R. Crompton, \& C. Lyonette (Eds.), Gender inequalities in the 21st century: New barriers and continuing constraints (pp. 153-173). Cheltenham: Edward Elgar.

Kuhn, T.S. (1961). The function of measurement in modern physical science. Isis, 52(2), 161-193.

Lewis, J. (2001). The decline of the male breadwinner model: The implications of work and care. Social Politics, 8(2), 152-170.

Lewis, J. (2008). Work-family balance policies: Issues and development in the UK 19972005 in comparative perspective. In J. Scott, S. Dex, \& H. Joshi (Eds.), Changing patterns of women's employment over 25 years (pp. 268-288). Cheltenham: Edward Elgar.

McCall, L. (2005). The complexity of intersectionality. Signs: Journal of Women and Culture and Society, 30, 1771-1802.

McDowell, L. (1992). Doing gender: Feminism, feminists and research methods. Transactions of the Institute of British Geographers, 17, 399-416.

McDowell, L. (2008). Thinking through work: Complex inequalities, constructions of difference and trans-national migrants. Progress in Human Geography, 32(4), 491-507.

Mies, M. (1983). Towards a methodology for feminist research. In G. Bowles \& R. DuelliKlein (Eds.), Theories of women's studies (pp. 117-139). London: Routledge.

Oakley, A. (1998). Gender, methodology and people's ways of knowing: Some problems with feminism and the paradigm debate in social science. Sociology, 32(4), 707-731.

Roberts, H. (Ed.). (1981). Doing feminist research. London: Routledge.

Scott, J. (2004). Gender inequality in production and reproduction: A new priority research network (GeNet Working Papers, No. 1). Retrieved December 23, 2009, from, http:// www.genet/ac/uk/GeNet2004p1.pdf

Scott, J., \& Dex, S. (2009). Paid and unpaid work: Can policy improve gender inequalities? In J. Miles \& R. Probert (Eds.), Money and family relationships (pp. 41-60). Hart.

Stanley, L., \& Wise, S. (1983). Breaking out: Feminist consciousness and feminist research. London: Routledge.

Therborn, G. (2004). Between sex and power: Family in the world 1900-2000. London: Routledge. 